\title{
Effect of adjuvant chemotherapy on carboxytelopeptide of cross-linked type I collagen of egyptian women with non-metastatic breast cancer
}

\author{
Ehab I. Mohamed ${ }^{1 *}$, Samir M. Abdel-Mageed ${ }^{2}$, Gihane I. Khalil ${ }^{3}$, Ahmed A. Emara ${ }^{4}$, Heba S. Ramadan ${ }^{1}$ and Nadia A. Abdel-Moneim ${ }^{5}$ \\ *Correspondence: eimohamed@yahoo.com; ehab.abdo@alexu.edu.eg

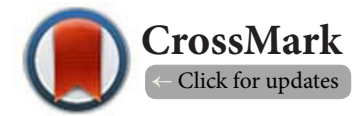

\begin{abstract}
${ }^{1}$ Medical Biophysics Department, Medical Research Institute, Alexandria University, Alexandria, Egypt. ${ }^{2}$ Physics Department, Faculty of Science, Alexandria University, Alexandria, Egypt. ${ }^{3}$ Chemical Pathology Department, Medical Research Institute, Alexandria University, Alexandria, Egypt. ${ }^{4}$ Radiodiagnosis and Medical Imaging Department, Faculty of Applied Medical Sciences, October 6 University, Cairo, Egypt. ${ }^{5}$ Cancer Management and Research Department, Medical Research Institute, Alexandria University, Alexandria, Egypt.
\end{abstract}

\begin{abstract}
Background: Women with breast cancer are at increased risk for the development of osteoporosis and skeletal fractures, as consequences of aromatase inhibition or chemotherapy-induced ovarian failure. We investigated the effect of adjuvant chemotherapy on biochemical markers of bone formation and resorption as well as on bone mineral density (BMD) of non-metastatic breast cancer (NMBC) postmenopausal Egyptian women.

Methods: We followed 100 newly diagnosed women with T1-3 NO-2 Mo breast cancer, who had a mean age $( \pm \mathrm{SD})$ of $55.06 \pm 8.78$ year, before and after receiving 6 -cycles of CAF chemotherapy treatment protocol. All participant women were subjected to blood biochemical analysis for determining serum levels of: erythrocyte sedimentation rate, calcium, alkaline phosphatase (ALP), bone specific alkaline phosphatase (S.ALP), Osteocalcin, carboxytelopeptide of collagen type I (CTX-I), 25-Hydroxyvitamin D, Parathyroid Hormone (PTH) and tumor marker CA 15-3. Segmental and total BMD were also investigated using Dual X-ray Absorptiometry technique.

Results: We found ALP, S.ALP, and CTx-I levels were significantly lower $(p<0.001)$, while PTH levels to be significantly higher for all women after chemotherapy as compared to their initial state before chemotherapy. Both segmental and total BMD, and consequently T- and Z-Scores after chemotherapy were significantly $(p<0.01)$ lower than their levels before chemotherapy. We developed prediction mathematical formulae for spine, pelvis and total BMD for all women before and after chemotherapy.

Conclusions: Adjuvant chemotherapy is responsible for decreasing both biochemical markers of bone formation and resorption as well as for decreasing segmental and total BMD in NMBC postmenopausal Egyptian women. We believe the mathematical formulae developed on basis of the two individual variables Age and BMI can be useful for assisting the clinician to frequently monitor bone health status of breast cancer patients in similar conditions.
\end{abstract}

Keywords: Chemotherapy, bone turnover, bone mineral density, osteoporosis, dual-energy X-ray absorptiometry, multivariate regression analysis

\section{Introduction}

Breast cancer (BC), which forms in ducts and lobules of breast tissues, occurs in both men and women, although male breast cancer is rare [1]. It is the most common cause of cancer death among women worldwide; its incidence rates being high in developed countries whereas rates in developing countries and in Japan are low but increasing. BC accounts for $37.6 \%$ of all reported tumors in Egyptian females, with an age-adjusted incidence rate of 49.6 per 100,000 females [2]. BC, prostate cancer, and multiple myeloma have particularly shown strong 
Mohamed et al. Breast Cancer Reports 2014,

association with skeletal metastases and related bone loss, resulting in fracture, hypercalcemia, pain, and declines in mobility and performance status $[3,4]$.

Although adjuvant chemotherapy represents a significant advance in the management of patients with $B C$, which has prolonged their survival by decreasing the systemic relapse, it causes a significant reduction in their bone mineral density (BMD) $[1,2]$. Thus, women with BC are at increased risk for the development of osteoporosis and skeletal fractures, giving rise to significant morbidity and some mortality [3], as a consequence of aromatase inhibition or chemotherapyinduced ovarian failure $[4,5]$. Exemestane and anastrozole, two chemotherapeutic aromatase inhibitors, have been shown to directly inhibit osteoclast differentiation and bone resoption markers leading to osteoporosis in postmenopausal women with non-metastatic breast cancer (NMBC) [6]. The bone resorption cross-linked carboxytelopeptide of collagen type I (CTX-I) combined with BMD measurements, can be used for assessing bone health status in postmenopausal women $[\mathbf{7 , 8}]$.

The objectives of this study were to investigate biochemical markers of bone formation and resorption as well as segmental and total BMD in NMBC postmenopausal Egyptian women before and after receiving a 6-cycles adjuvant chemotherapy treatment protocol.

\section{Methods}

\section{Patients and material}

The study population was comprised of 100 postmenopausal women [mean age $( \pm$ SD) $55.06 \pm 4.78$ year and body mass index (BMI) $38.28 \pm 4.13 \mathrm{~kg} / \mathrm{m}^{2}$ ] with newly diagnosed T1-3 NO-2 MO $B C$, who were studied longitudinally before and after receiving 6-cycles of a three-drug combination protocol containing Cyclophosphamide $\left(600 \mathrm{mg} / \mathrm{m}^{2}\right)$, Adriamycin $\left(40 \mathrm{mg} / \mathrm{m}^{2}\right)$, and 5-Fluoruoracil $\left(600 \mathrm{mg} / \mathrm{m}^{2}\right)(\mathrm{CAF})$, as detailed elsewhere $[9,10]$. Participants were recruited from the Department of Cancer Management and Research, Medical Research Institute, Alexandria University, Alexandria, Egypt; where they were hospitalized for diagnosis and/or treatment; and were referred to the Medical Biophysics and Chemical Pathology Departments, Medical Research Institute, Alexandria University, Alexandria, Egypt for subsequent bone densitometric measurements and blood biochemical analysis, respectively. The study was conducted in accordance with ethical guidelines of the 1975 declaration of Helsinki and the Ethics Committee of the Medical Research Institute, Alexandria University approved the study protocol. All participant women were asked to freely volunteer to the study protocol and provided a signed informed consent prior to their enrollment.

Clinical staging of BC was carried out according to the recent guidelines of the AJCC on basis of: a detailed physical examination, imaging studies, operative findings and pathologic examination of the breast and other tissues [11]. Exclusion criteria from the study protocol were the following: (1) serum creatinine greater than $150 \mathrm{mmol} / \mathrm{L}$; (2) peptic ulcer;
(3) hysterectomy or bilateral oophorectomy; (4) osteoporosis; (5) untreated hypothyreosis; (6) bisphosphonate, calcitonin or peroral steroid therapy; (7) pregnancy or lactation; and (8) other malignancies.

All participant women were interviewed regarding general health, bone aches, history of fractures, medications, and menopausal status and were subjected to a complete physical examination stressing on bone, joints, and neurological examination. The following analyses were carried out, using standard methods.

\section{Blood biochemical analyses}

Fasting blood samples were collected from all participant women to determine serum levels of: erythrocyte sedimentation rate (ESR, $\mathrm{mm} / \mathrm{hr}$ ) [12] and total calcium $(\mathrm{Ca}, \mathrm{mg} / \mathrm{dl})$ [13] using a semi-automatic chemical analyzer (Olympus AU 400, Olympus Life and Material Science, Europe GmbH, Hamburg, Germany); osteocalcin (OC, ng/ml) [14], 25-hydroxyvitamin D (25-VitD, pg/ml) [15], parathyroid hormone (PTH, pg/ml) [16] and tumor marker CA15-3 (U/ml) [17] by chemiluminescence technique (Immulite 1000, Siemens Healthcare Diagnostics Inc., Flanders, NJ, USA); and total alkaline phosphatase (ALP, $\mathrm{U} / \mathrm{I})$, bone specific alkaline phosphatase (S.ALP, $\mu \mathrm{g} / \mathrm{L}$ ) [16] and carboxytelopeptide of collagen type I (CTx-l, ng/ml) [18] by ELISA technique (ELISA ELx 800, Bio-Tek Instruments Inc., Winooski, UT, USA).

\section{Imaging, body-composition and bone densitometric measurements}

Imaging studies were carried out for all participant women using chest X-ray, abdominal and pelvic ultrasound and mammography. Demographic and body-composition variables were also measured for all participant women. Specifically, body weight $(\mathrm{kg})$ (participants clothed in underwear, bare feet) was measured using a digital scale sensitive to the nearest $0.01 \mathrm{~kg}$ (Electronic Body Scale, TCS-200-RT, China). Height (m) was measured using a stadiometer. BMI was calculated as Weight $/$ Height $^{2}\left(\mathrm{~kg} / \mathrm{m}^{2}\right)$. Segmental (i.e., head, arms, trunk, ribs, spine, pelvis and legs) and total bone mineral content (BMC) and BMD, as well as fat mass (FM), lean bone-free mass (LBFM) and tissue bone-free mass (TBFM) were assessed using a Dual-energy X-ray Absorptiometry (DXA) total body scanner (Lunar DXP Pro, GE Health Care, USA), as detailed earlier by our group [19-22].

\section{Statistical analysis}

Data analysis was carried out using the StatView ${ }^{\circledR}$ statistical software package (SAS Institute Inc., Cary, NC, USA). Descriptive statistics were calculated for the mean \pm SD of all relevant variables and their frequency distributions were examined. Analysis of the continuous variables showed them to be normally distributed. Paired Student's t-test of significance was used to compare differences before and after adjuvant chemotherapy for various variables. Differences were considered to be sign- 
ificant only ifp values were less than 0.05 . Furthermore, multivariate linear regression analysis was performed to examine the interrelations among demographic variables and segmental and total BMD for NMBC women using simple and partial correlation coefficients. Prediction equations based on two independent variables (i.e., Age and BMI) were developed and their cumulative correlation coefficients (R) and standard error of estimation (SEE) were calculated, as detailed elsewhere $[20,22]$.

\section{Results}

Demographic and body-composition data for NMBC women before and after chemotherapy are shown in Table 1. Although numerically low, neither weight nor its tissue components (i.e., FM, LBFM, and TBFM) were statistically different after chemotherapy. However, segmental and total BMC and BMD, consequently, total T- and Z-Scores, were all significantly $(p<0.05)$ lower after chemotherapy as compared to their levels before chemotherapy (data only for BMD are shown in Figure 1). Biochemical analysis (Table 2) showed comparable levels of serum ESR, Ca, OC, 25-VitD and CA15-3; yet ALP, S.ALP and $C T x-I$ levels were significantly lower after chemotherapy as

Table 1. Demographic and body-composition parameters measured for women $(n=100)$ before and after receiving 6-cycles of a three-drug cyclophosphamide, adriamycin, and 5-fluoruoracil (CAF) chemotherapy treatment protocol.

\begin{tabular}{lcccc}
\hline \multicolumn{2}{c}{ Before chemotherapy } & \multicolumn{2}{c}{ After chemotherapy } \\
\hline $\begin{array}{l}\text { Age } \\
\text { year })\end{array}$ & $55.06 \pm 4.78$ & $(48.80-72.84)$ & $55.63 \pm 4.60$ & $(49.07-73.10)$ \\
$\begin{array}{l}\text { Weight } \\
(\mathrm{kg})\end{array}$ & $94.25 \pm 13.77$ & $(66.80-118.10)$ & $88.01 \pm 18.82$ & $(44.30-112.90)$ \\
$\begin{array}{l}\text { Height } \\
(\mathrm{m})\end{array}$ & $1.57 \pm 0.07$ & $(1.32-1.67)$ & $1.53 \pm 0.05$ & $(1.32-1.64)$ \\
$\begin{array}{l}\text { Body mass } \\
\text { index }\end{array}$ & $38.28 \pm 4.13$ & $(28.65-46.84)$ & $37.51 \pm 6.24$ & $(24.37-42.96)$ \\
$\begin{array}{l}\text { (BMI, } \\
\left.\mathrm{kg} / \mathrm{m}^{2}\right)\end{array}$ & & & & \\
$\begin{array}{l}\text { Fat mass } \\
(\mathrm{FM}, \mathrm{kg})\end{array}$ & $45.27 \pm 9.06$ & $(25.61-62.16)$ & $42.88 \pm 12.60$ & $(15.79-61.40)$ \\
$\begin{array}{l}\text { Lean } \\
\text { bone-free } \\
\text { mass }\end{array}$ & $43.40 \pm 6.70$ & $(31.43-60.23)$ & $39.36 \pm 7.65$ & $(21.09-58.66)$ \\
$\begin{array}{l}\text { (LBFM, } \\
\mathrm{kg})\end{array}$ & & & & \\
$\begin{array}{l}\text { Tissue } \\
\text { bone-free } \\
\text { mass } \\
\text { (TBFM, } \\
\mathrm{kg})\end{array}$ & $88.67 \pm 12.86$ & $(64.81-107.98)$ & $82.25 \pm 17.60$ & $(40.97-104.78)$ \\
$\begin{array}{l}\text { T-Score } \\
\text { Z-Score }\end{array}$ & $1.25 \pm 1.36$ & $(-1.60-2.70)$ & $0.55 \pm 1.20^{*}$ & $(-1.90-3.20)$ \\
\hline
\end{tabular}

Values are expressed as Mean $\pm \mathrm{SD}$ and numbers in parenthesis are ranges (minimum-maximum).

Statistical analysis was carried out using unpaired Student's t-test of significance. ${ }^{\star} p<0.001$ versus women before chemotherapy.

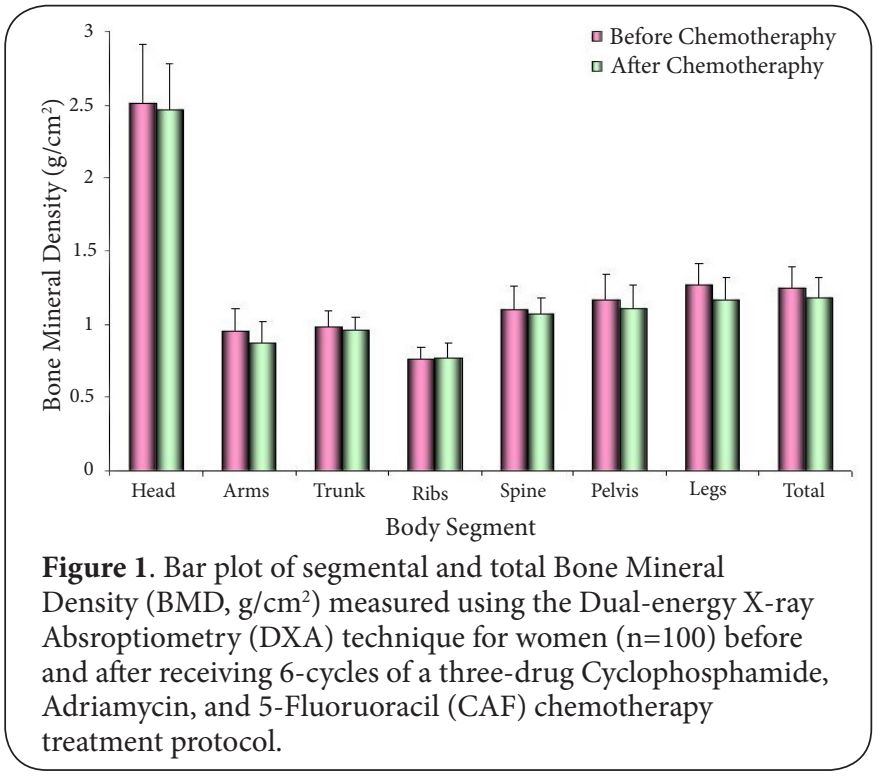

compared to their levels before chemotherapy. Only PTH serum levels were significantly higher after chemotherapy in comparison with its levels before chemotherapy.

Table 3 shows coefficients for the initial multiple regression analysis to determine the effect of simultaneously adding the covariates: Age, BMI, weight, Height, FM, LBFM and TBFM on lumbar spine $B M D$, pelvis $B M D$, and total $B M D$, respectively, as the dependent variables, separately for women before and after chemotherapy. Of these, we found the covariates: Age and BMI to be correlated significantly with lumbar spine $B M D$, pelvis $B M D$, and total $B M D(R=0.99, p<0.0001$ for all associations). Table 4 shows the continuous prediction equations developed for lumbar spine BMD, pelvis BMD, and total BMD based on these two independent variables for NMBC women before and after chemotherapy.

\section{Discussion}

Osteoporosis is a global public health concern currently affecting more than 200 million people worldwide, about $80 \%$ of them are women [23]. Not only patients with cancer may be at risk for primary osteoporosis, but also for secondary osteoporosis due to cancer therapies; which may alter the gonadal function and negatively affect bone turnover [24-27]. BMD testing is considered highly effective for establishing a diagnosis of osteoporosis and monitoring its progression, since an inverse relationship exists between $B M D$ and future fracture risk. BMD is expressed as a T- or Z-Score, which are the standard deviation of BMD from the expected BMD for a young adult or an age-matched normal population of the same sex, respectively.

Although, data of body-composition (i.e., FM, LBFM, and TBFM) were comparable before and after chemotherapy (Table 1), segmental and total BMC and BMD distribution were significantly $(p<0.05)$ lower after chemotherapy in comparison 
Mohamed et al. Breast Cancer Reports 2014,

http://www.hoajonline.com/journals/pdf/2057-1631-1-1.pdf

Table 2. Biochemical parameters measured in serum for women $(n=100)$ before and after receiving 6-cycles of a three-drug cyclophosphamide, adriamycin, and 5-fluoruoracil (CAF) chemotherapy treatment protocol.

\begin{tabular}{lllll}
\hline & \multicolumn{2}{l}{ Before chemotherapy } & \multicolumn{2}{l}{ After chemotherapy } \\
\hline Erythrocyte cedimentation cate $(\mathrm{ESR}, \mathrm{mm} / \mathrm{hr})$ & $73.57 \pm 25.91$ & $(23-120)$ & $59.68 \pm 35.68$ & $(17-130)$ \\
Calcium $(\mathrm{Ca}, \mathrm{mg} / \mathrm{dl}$ ) & $9.42 \pm 0.3$ & $(8.6-9.8)$ & $9.43 \pm 0.37$ & $(8.8-9.9)$ \\
Alkaline phosphatase (ALP, $\mathrm{U} / \mathrm{l})$ & $78.82 \pm 24.05$ & $(41-127)$ & $58.90 \pm 20.42^{*}$ & $(30-101)$ \\
Bone specific alkaline phosphatase (B.ALP, $m g / l)$ & $43.33 \pm 6.43$ & $(36-48)$ & $29.33 \pm 9.30^{*}$ & $(23-40)$ \\
Osteocalcin (OC, $n g / m l)$ & $11.91 \pm 2.2$ & $(7.5-16.3)$ & $9.92 \pm 1.02$ & $(7.8-11.9)$ \\
Carboxytelopeptide of collagen Type I (CTx-I, $n g / m l)$ & $1.26 \pm 0.53$ & $(0.33-2.11)$ & $0.61 \pm 0.07^{*}$ & $(0.07-1.28)$ \\
25-Hydroxyvitamin D $(25-\mathrm{VitD}, n g / m l)$ & $28.49 \pm 3.25$ & $(21.99-34.98)$ & $29.01 \pm 3.14$ & $(22.72-35.26)$ \\
Parathyroid hormone (PTH, $p g / m l)$ & $59.50 \pm 27.01$ & $(19.1-113)$ & $86.34 \pm 35.02^{*}$ & $(24.8-143)$ \\
Tumor marker CA15-3 (CA15-3, $\mathrm{U} / \mathrm{ml})$ & $24.99 \pm 8.74$ & $(14.1-41.7)$ & $32.51 \pm 17.84$ & $(15.6-88.5)$ \\
\hline
\end{tabular}

Values are expressed as Mean \pm SD and numbers in parenthesis are ranges (minimum-maximum).

Statistical analysis was carried out using unpaired Student's t-test of significance. ${ }^{*} \mathrm{p}<0.001$ versus women before chemotherapy.

Table 3. Coefficients of initial multiple linear regression of predictors for lumbar spine, pelvis, and total bone mineral density (BMD) for women $(n=100)$ before and after receiving 6-cycles of a three-drug cyclophosphamide, adriamycin, and 5-fluoruoracil (CAF) chemotherapy treatment protocol.

\begin{tabular}{|c|c|c|c|c|c|c|}
\hline & \multicolumn{3}{|c|}{ Before chemotherapy } & \multicolumn{3}{|c|}{ After chemotherapy } \\
\hline & b & SEE & $p$ & b & SEE & $p$ \\
\hline \multicolumn{7}{|l|}{ Lumbar spine BMD } \\
\hline Age (year) & 0.002 & 0.004 & 0.001 & 0.008 & 0.006 & 0.015 \\
\hline Body mass index (BMI, $\mathrm{kg} / \mathrm{m}^{2}$ ) & 0.027 & 0.003 & 0.006 & 0.016 & 0.003 & 0.033 \\
\hline Weight $(\mathrm{kg})$ & 0.018 & 0.032 & 0.592 & -0.023 & 0.021 & 0.297 \\
\hline Height $(m)$ & 0.006 & 0.021 & 0.583 & -0.003 & 0.016 & 0.451 \\
\hline Fat mass (FM, kg) & -0.046 & 0.186 & 0.808 & 0.074 & 0.329 & 0.823 \\
\hline Lean bone-free mass (LBFM, $k g$ ) & 0.012 & 0.003 & 0.356 & 0.014 & 0.003 & 0.491 \\
\hline Tissue bone-free mass (TBFM, $\mathrm{kg}$ ) & 0.008 & 0.004 & 0.266 & 0.007 & 0.005 & 0.311 \\
\hline \multicolumn{7}{|l|}{ Pelvis BMD } \\
\hline Age (year) & -0.002 & 0.005 & 0.001 & 0.009 & 0.005 & 0.013 \\
\hline Body mass index (BMI, $\mathrm{kg} / \mathrm{m}^{2}$ ) & 0.033 & 0.026 & 0.005 & 0.016 & 0.014 & 0.047 \\
\hline Weight $(\mathrm{kg})$ & 0.013 & 0.003 & 0.486 & 0.007 & 0.002 & 0.812 \\
\hline Height $(m)$ & 0.002 & 0.019 & 0.611 & 0.010 & 0.005 & 0.412 \\
\hline Fat mass (FM, $k g$ ) & -0.005 & 0.227 & 0.984 & 0.089 & 0.288 & 0.761 \\
\hline Lean bone-free mass (LBFM, $\mathrm{kg}$ ) & 0.012 & 0.213 & 0.198 & 0.014 & 0.215 & 0.122 \\
\hline Tissue bone-free mass (TBFM, $\mathrm{kg}$ ) & 0.008 & 0.114 & 0.119 & 0.007 & 0.115 & 0.112 \\
\hline \multicolumn{7}{|l|}{ Total BMD } \\
\hline Age (year) & -0.001 & 0.002 & 0.001 & 0.006 & 0.003 & 0.001 \\
\hline Body mass index (BMI, $\mathrm{kg} / \mathrm{m}^{2}$ ) & 0.034 & 0.002 & 0.001 & 0.022 & 0.002 & 0.001 \\
\hline Weight $(k g)$ & -0.443 & 0.101 & 0.233 & 0.283 & 0.190 & 0.151 \\
\hline Height $(m)$ & 0.006 & 0.002 & 0.451 & -0.011 & 0.012 & 0.386 \\
\hline Fat mass (FM, $k g$ ) & -0.048 & 0.018 & 0.712 & -0.004 & 0.002 & 0.978 \\
\hline Lean bone-free mass (LBFM, $\mathrm{kg}$ ) & -0.035 & 0.011 & 0.306 & 0.004 & 0.009 & 0.639 \\
\hline Tissue bone-free mass (TBFM, $\mathrm{kg}$ ) & -0.032 & 0.012 & 0.505 & 0.003 & 0.008 & 0.522 \\
\hline
\end{tabular}

$\beta$ : regression coefficient; SEE: Standard error of estimation; $\mathrm{p}$ : significance level at $<0.05$ for individual parameter 
Table 4. Final prediction equations based on two independent variables for lumbar spine, pelvis, and total bone mineral density (BMD) for women $(n=100)$ before and after receiving 6-cycles of a three-drug cyclophosphamide, adriamycin, and 5-fluoruoracil (CAF) chemotherapy treatment protocol.

\begin{tabular}{lllllll}
\hline & \multicolumn{1}{c}{ Prediction equation $^{\mathrm{a}}$} & $\boldsymbol{R}^{2}$ & SEE & WSSE & Entry \\
\hline Before chemotherapy & $B M D_{\text {Spine }}$ & $=0.002 \times A g e+0.027 \mathrm{x} B M I$ & 0.98 & 0.16 & 18.20 & 1 \\
After chemotherapy & & $=0.008 \times$ Age $+0.016 \times B M I$ & 0.98 & 0.11 & 51.30 & 2 \\
Before chemotherapy & $B M D_{\text {Pelvis }}$ & $=-0.002 \times A g e+0.033 \times B M I$ & 0.98 & 0.15 & 18.08 & 3 \\
After chemotherapy & & $=0.009 \times$ Age $+0.016 \times B M I$ & 0.97 & 0.17 & 29.73 & 4 \\
Before chemotherapy & $B M D_{\text {Total }}$ & $=-0.001 \times A g e+0.034 \times B M I$ & 0.99 & 0.11 & 19.43 & 5 \\
After chemotherapy & & $=0.006 \times A g e+0.022 \times B M I$ & 0.99 & 0.11 & 35.63 & 6 \\
\hline
\end{tabular}

aAll prediction equations are significant $(p<0.0001)$ using unpaired Student's t-test versus women before chemotherapy. Age is in years and body mass index (BMI) is in $\mathrm{kg} / \mathrm{m}^{2}$. $\mathrm{R}^{2}$ : coefficient of determination; SEE: Standard error of estimation; WSSE: Weighed sum of squared errors

with their levels before chemotherapy. Consequently, total T-and Z-Scores after chemotherapy were also significantly $(p<0.001)$ lower than those before chemotherapy, confirming that bone loss was directly related to treatment with adjuvant chemotherapy. In line with this, many studies reported that adjuvant chemotherapy may cause a rapid bone loss, increasing the risk of osteoporosis for pre- and postmenopausal women with $B C$ later in life [1-7,24-27]. It has been shown that bone loss with aging occurs because hypogonadism may progress to primary osteoporosis. However, secondary osteoporosis due to cancer therapies-induced bone loss results from other factors (e.g., chronic diseases, nutritional deficiencies, drugs, etc.) that negatively alter bone remodeling. Both cases cause elevation of PTH levels, greater bone resorption than synthesis, impaired neuromuscular functioning, and increased risk for falls and fractures [25-27].

Biochemical analysis showed that, albeit comparable levels of serum Ca and 25-VitD, both ALP and S.ALP were significantly lower after chemotherapy as compared to their initial levels before chemotherapy. CTx-I levels were also significantly lower after chemotherapy, denoting a condition of decreased bone resorption in post-chemotherapy NMBC women (Table 2). Although both markers of bone formation and resorption were significantly lower after chemotherapy as compared to their levels before chemotherapy, consequently denoting a lower bone turnover activity, which was evidenced by the significantly lower segmental and total BMD for postchemotherapy NMBC women (Figure 1). In line with this, Greep et al., [25] previously reported that postmenopausal women with early $B C$ who received adjuvant chemotherapy had lower $B M D$ in comparison with their counterparts who did not receive any chemotherapy. Moreover, Rodríguez-Rodríguez et al., [1], had also previously detected significant decreases in $B M D$ at lumbar, trochanter, intertrochanter and total hip after adjuvant treatment for NMBC women. The significantly higher PTH levels after chemotherapy (i.e., $86.34 \pm 35.02$ vs. $59.50 \pm 27.01 \mathrm{pg} / \mathrm{ml}$ for that before chemotherapy, $p<0.001$ ) may justify the observed decrease of bone formation in postchemotherapy NMBC patients as compared to their status before chemotherapy.

The use of markers of bone turnover for monitoring bone metastases in $\mathrm{BC}$ and in response to therapy had been shown earlier [28-30]. Chemotherapeutic aromatase inhibitors (e.g., exemestane and anastrozole) have been shown to directly inhibit osteoclast differentiation and bone resoption markers leading to osteoporosis in postmenopausal women with early BC [6], yet with apparently increased bone resorption biochemical markers, as also had been shown earlier [31,32]. It has been shown that osteoporotic bone loss and bone metastasis ultimately share a pathophysiologic pathway that stimulates bone resorption by increasing the formation and activity of osteoclasts [4]. Osteolytic lesions commonly seen in BC can cause severe pain, pathologic fracture, and compression syndromes of the nerve root or spinal cord, as well as metabolic disturbances (e.g., hypercalcemia, phosphate imbalances, disruptions in acid/base and neurological homeostasis, and nephrolithiasis) [33]. Combined osteolytic and osteoblastic lesions, which cause increased bone resorption through osteoclasts within osteoblastic lesions and compensatory, secondary bone formation through osteoblasts within osteolytic lesions, have been observed in BC patients $[33,34]$. Therefore, it is advised that women with $B C$ who are undergoing hormonal therapy, chemotherapy, radiation, and bisphosphonate therapy should be closely monitored for BMD loss and skeletal health maintenance prescriptions [5]. It is noteworthy, current recommendations for avoiding the skeletal complications of $\mathrm{BC}$ therapy include adequate intake of $C a$ and vitamin $D$, regular weight-bearing exercise, cessation of smoking, reduction in alcohol intake, and bisphosphonate treatment for those found to be osteoporotic $[5,34]$.

As a fast and reasonably accurate method for frequently monitoring bone health, we developed prediction mathematical formulae for spine and pelvis BMD, which are the sites most susceptible to fracture risks, together with the total BMD of 
Mohamed et al. Breast Cancer Reports 2014,

NMBC women. Multiple linear regression analysis showed that the covariates age and BMI were significantly associated with BMDspine, BMDpelvis, and BMDtotal independently $(\mathrm{R}=0.99$, $p<0.0001$ for all associations). Table 3 shows the continuous prediction equations developed for BMDspine, BMDpelvis and BMDtotal based on two independent variables for NMBC women before and after chemotherapy. These equations gave estimations, which were on average $<-0.70 \%$ for BMD spine, $<0.30 \%$ for BMDpelvis, and $<2.00 \%$ for BMDtotal of all participants, which did not result in false negative or positive diagnosis of BMD status. Similar studies carried out on postmenopausal healthy and cirrhotic Italian women [20] as well as on Egyptian patients with $\beta$-Thalassemia Major [22] using anthropometric variables have proven useful for the continuous monitoring of their bone health with comparable levels of SEE. We believe these formulae will permit the physician to identify patients at risk of fracture, so that preventive strategies or treatment can be targeted towards those at greatest fracture risk.

One of the limitations of the present study is the small sample size, being focused only on NMBC women who don't have: serum creatinine greater than $150 \mu \mathrm{mol} / \mathrm{L}$; peptic ulcer; hysterectomy or bilateral oophorectomy; osteoporosis; untreated hypothyreosis; bisphosphonate, calcitonin or peroral steroid therapy; pregnancy or lactation; and any other malignancies. Thus, to validate the developed formulae, there is a need to study a bigger population of BC women, possibly extending and taking into consideration other factors like bone metastasis and the accompanying physiologic mechanisms responsible for lowering segmental and total BMD.

\section{Conclusions}

Adjuvant chemotherapy is responsible for decreasing segmental and total BMD in BC postmenopausal women, which can be clinically evaluated by the significant changes in both T- and Z-Scores as well as biochemical markers of bone turnover. The decrease in segmental and total BMD was mainly due to significant decrease in the levels of ALP and S.ALP rather than an increase in CTx-I markers. Thus, measurements of BMD and biochemical markers of bone formation and resorption for BC women before starting any adjuvant chemotherapy is important to assess initial status of bone health. We believe, the simple mathematical formulae developed on basis of the two individual variables Age and BMI can be useful for assisting the clinician to frequently monitor bone health status of BC patients in similar conditions, being able to manage possible bone losses rapidly and efficiently.

\section{List of abbreviations}

25-VitD: 25-Hydroxyvitamin D

ALP: Alkaline phosphatase

BC: Breast cancer

BMC: Bone mineral content

BMD: Bone mineral density

BMI: Body mass index
CA15-3:Tumor Marker CA15-3

Ca: Calcium

CAF: Cyclophosphamide, Adriamycin and 5-Fluoruoracil

CTx-I: Carboxytelopeptide of collagen type I

DXA: Dual-energy X-ray Absorptiometry

ESR: Erythrocyte sedimentation rate

FM: Fat mass

LBFM: Lean bone-free mass

NMBC: Non-metastatic breast cancer

OC: Osteocalcin

PTH: Parathyroid hormone

R: Correlation coefficient

S.ALP: bone specific alkaline phosphatase

TBFM: Tissue bone-free mass

\section{Competing interests}

The authors declare that they have no competing interests.

Authors' contributions

\begin{tabular}{|l|c|c|c|c|c|c|}
\hline Authors' contributions & EIM & SMA & GIK & AME & HSR & NAA \\
\hline Research concept and design & $\checkmark$ & -- & -- & -- & -- & $\checkmark$ \\
\hline Collection and/or assembly of data & $\checkmark$ & $\checkmark$ & $\checkmark$ & $\checkmark$ & $\checkmark$ & $\checkmark$ \\
\hline Data analysis and interpretation & $\checkmark$ & $\checkmark$ & $\checkmark$ & $\checkmark$ & $\checkmark$ & $\checkmark$ \\
\hline Writing the article & $\checkmark$ & $\checkmark$ & -- & -- & $\checkmark$ & -- \\
\hline Critical revision of the article & $\checkmark$ & $\checkmark$ & -- & -- & -- & $\checkmark$ \\
\hline Final approval of article & $\checkmark$ & $\checkmark$ & $\checkmark$ & $\checkmark$ & $\checkmark$ & $\checkmark$ \\
\hline
\end{tabular}

Acknowledgement

Part of this study has been presented in an abstract form at the $4^{\text {th }}$ International Symposium on "In Vivo Body Composition Studies" in the period 21-24 May, 2011; Hangzhou; China.

Publication history

EIC: Paul J. Higgins, Albany Medical College, USA.

Received: 19-Aug-2014 Final Revised: 29-Sep-2014

Accepted: 06-Oct-2014 Published: 14-Oct-2014

\section{References}

1. Rodriguez-Rodriguez LM, Rodriguez-Rodriguez EM, Oramas-Rodriguez JM, Santolaria-Fernandez F, Llanos M, Cruz J, Martinez A, GonzalezReimers $\mathrm{E}$, Gomez A and Batista N. Changes on bone mineral density after adjuvant treatment in women with non-metastatic breast cancer. Breast Cancer Res Treat. 2005; 93:75-83. | Article | PubMed

2. Rennert G. Breast Cancer. In: Freedman LS, Edwards BK, Ries LAG, Young $J \mathrm{~L}$ (Eds), Cancer Incidence in Four Member Countries (Cyprus, Egypt, Israel, and Jordan) of the Middle East Cancer Consortium (MECC) Compared with US SEER. National Cancer Institute. 2006; 73-81. I Pdf

3. Hadji P, Ziller M, Albert US and Kalder M. Assessment of fracture risk in women with breast cancer using current vs emerging guidelines. $\mathrm{Br} \mathrm{J}$ Cancer. 2010; 102:645-50. | Article | PubMed Abstract | PubMed Full $\underline{\text { Text }}$

4. Lipton A, Uzzo R, Amato RJ, Ellis GK, Hakimian B, Roodman GD and Smith $M R$. The science and practice of bone health in oncology: managing bone loss and metastasis in patients with solid tumors. J Nat/ Compr Canc Netw. 2009; 7 Suppl 7:S1-29; quiz S30. | PubMed Abstract | PubMed Full Text

5. Hirbe A, Morgan EA, Uluckan O and Weilbaecher K. Skeletal complications of breast cancer therapies. Clin Cancer Res. 2006; 12:6309s-6314s. | Article | PubMed Abstract | PubMed Full Text

6. Aihara T, Suemasu K, Takei H, Hozumi Y, Takehara M, Saito T, Ohsumi $\mathrm{S}$, Masuda $\mathrm{N}$ and Ohashi Y. Effects of exemestane, anastrozole and tamoxifen on bone mineral density and bone turnover markers in postmenopausal early breast cancer patients: results of N-SAS BC 04, the TEAM Japan substudy. Oncology. 2010; 79:376-81. | Article | PubMed 
Mohamed et al. Breast Cancer Reports 2014,

7. Bauer DC, Black DM, Garnero P, Hochberg M, Ott S, Orloff J, Thompson $D E$, Ewing SK and Delmas PD. Change in bone turnover and hip, nonspine, and vertebral fracture in alendronate-treated women: the fracture intervention trial. J Bone Miner Res. 2004; 19:1250-8. | Article I PubMed

8. Seibel MJ. Biochemical markers of bone turnover: part I: biochemistry and variability. Clin Biochem Rev. 2005; 26:97-122. | PubMed Abstract | PubMed Full Text

9. Abd-El-Moneim NA, Hussein NG, Morsi MI, El-Kohly ZA, Shaheen NE, Abou-Raoash NM and El-Sayed LH. Effect of two chemotherapeutic regimens on some biochemical and immunological parameters in breast cancer patients. Med. Sci. Res. (England). 1998; 6:301-307.

10. Eifel P, Axelson JA, Costa J, Crowley J, Curran WJ, Jr., Deshler A, Fulton S, Hendricks CB, Kemeny M, Kornblith AB, Louis TA, Markman M, Mayer $R$ and Roter D. National Institutes of Health Consensus Development Conference Statement: adjuvant therapy for breast cancer, November 1-3, 2000. J Nat/ Cancer Inst. 2001; 93:979-89. | Article | PubMed

11. Singletary SE and Connolly JL. Breast cancer staging: working with the sixth edition of the AJCC Cancer Staging Manual. CA Cancer J Clin. 2006; 56:37-47; quiz 50-1. | Article | PubMed

12. Lewis SM, Bain BJ and Bates I. Dave and Lewis Practical Hematology Textbook. $9^{\text {th }}$ Ed. Harcourt Publisher Ltd., London. 2001; 30-41. | Book

13. Leary NO, Pembroke A and Duggan PF. Single stable reagent (Arsenazo III) for optically robust measurement of calcium in serum and plasma. Clin Chem. 1992; 38:904-8. I PubMed

14. Lee AJ, Hodges $S$ and Eastell R. Measurement of osteocalcin. Ann Clin Biochem. 2000; 37:432-46. | Article | PubMed

15. Ameson WL and Ameson DL. Current Methods for Routine Clinical Laboratory Testing of Vitamin D Levels. Lab. Medicine. 2013; 44:e38-e42.

16. Burtis C, Ashwood E and Bruns D. Tietz Texbook of Clinical Chemistry and Molecular Diagnostics. $4^{\text {th }}$ Ed., Elsevier Saunders Company. St. Louis, 2006; 609-611. | Book

17. Nicolini A, Colombini C, Luciani L, Carpi A and Giuliani L. Evaluation of serum CA15-3 determination with CEA and TPA in the post-operative follow-up of breast cancer patients. Br J Cancer. 1991; 64:154-8. | Article | PubMed Abstract | PubMed Full Text

18. Delmas PD. Markers of bone turnover for monitoring treatment of osteoporosis with antiresorptive drugs. Osteoporos Int. 2000; 11 Suppl 6:S66-76. | Article | PubMed

19. Mohamed El, Maiolo C, lacopino L, Pepe M, Di Daniele N and De Lorenzo A. The impact of body-weight components on forced spirometry in healthy italians. Lung. 2002; 180:149-59. | Article | PubMed

20. Casini A, Mohamed El, Gandin C, Tarantino U, Di Daniele N and De Lorenzo A. Predicting bone mineral density of postmenopausal healthy and cirrhotic Italian women using anthropometric variables. Dig Liver Dis. 2003; 35:881-7. | Article | PubMed

21. Mohamed El and Khalil ES. Bone densitometric analysis in egyptian hemodialysis patients. Int J Biomed Sci. 2008; 4:120-4. | PubMed Abstract | PubMed Full Text

22. Mohamed El, Mahmoud GN, Khalil GI and Sallam SM. Mathematical modeling of segmental and total bone mineral density in Egyptian patients with $\beta$-Thalassaemia Major. J. Biophys. Biomed. Sci 2008; 1:6974.

23. Lane JM, Serota AC and Raphael B. Osteoporosis: differences and similarities in male and female patients. Orthop Clin North Am. 2006; 37:601-9. | Article | PubMed

24. Mincey BA, Moraghan TJ and Perez EA. Prevention and treatment of osteoporosis in women with breast cancer. Mayo Clin Proc. 2000 75:821-9. | Article | PubMed

25. Greep NC, Giuliano AE, Hansen NM, Taketani T, Wang HJ and Singer FR. The effects of adjuvant chemotherapy on bone density in postmenopausal women with early breast cancer. Am J Med. 2003; 114:653-9. | Article | PubMed

26. Wickham R. Osteoporosis related to disease or therapy in patients with cancer. Clin J Oncol Nurs. 2011; 15:E90-E104. | Article | PubMed
27. Winters-Stone KM, Dobek J, Nail L, Bennett JA, Leo MC, Naik A and Schwartz A. Strength training stops bone loss and builds muscle in postmenopausal breast cancer survivors: a randomized, controlled trial. Breast Cancer Res Treat. 2011; 127:447-56. | Article | PubMed Abstract | PubMed Full Text

28. Fontana A and Delmas PD. Markers of bone turnover in bone metastases. Cancer. 2000; 88:2952-60. | Article | PubMed

29. Lipton A, Costa L, Ali S and Demers L. Use of markers of bone turnover for monitoring bone metastases and the response to therapy. Semin Oncol. 2001; 28:54-9. | Article | PubMed

30. Oremek GM, Weis A, Sapoutzis N and Sauer-Eppel H. Diagnostic value of bone and tumour markers in patients with malignant diseases. Anticancer Res. 2003; 23:987-90. | PubMed

31. Watts NB. Clinical utility of biochemical markers of bone remodeling. Clin Chem. 1999; 45:1359-68. | Article | PubMed

32. Voorzanger-Rousselot $\mathrm{N}$, Juillet $\mathrm{F}$, Mareau E, Zimmermann J, Kalebic $T$ and Garnero P. Association of 12 serum biochemical markers of angiogenesis, tumour invasion and bone turnover with bone metastases from breast cancer: a crossectional and longitudinal evaluation. Br J Cancer. 2006; 95:506-14. | Article | PubMed Abstract | PubMed Full Text

33. Roodman GD. Mechanisms of bone metastasis. N Engl J Med. 2004; 350:1655-64. | Article | PubMed

34. Coleman RE. Bisphosphonates: clinical experience. Oncologist. 2004; 9 Suppl 4:14-27. | Article | PubMed

\section{Citation:}

Mohamed EI, Abdel-Mageed SM, Khalil GI, Emara AA, Ramadan HS and Abdel-Moneim NA. Effect of adjuvant chemotherapy on carboxytelopeptide of cross-linked type I collagen of egyptian women with non-metastatic breast cancer. Breast Cancer Rep. 2014; 1:1.

http://dx.doi.org/10.7243/2057-1631-1-1 